\title{
The Power of Planning: Self-Control by Effective Coall-striving
}

Peter M. Gollwitzer, Caterina Gawrilow, and Gabriele Oettingen

\section{ABSTRACT}

As highlighted by Kurt Lewin, goal attainment is not yet secured solely by forming strong commitnents to highly desirable and feasible goals. There is always the subsequent issue of implementing a set goal, and one wonders what people can do to enhance their chances of being successful at this second phase of goal pursuit. A promising answer seems to be the following: People may plan out in advance low they want to solve the problems of goal implementation. But what are these problems? There are at least four problems that stand out. These problems include getting started with goal striving, staying on track, calling a halt, and not overextending oneself. We will describe research showing that making ifthen plans (i.e., form implementation intentions) on how to deal with these problems indeed facilitates solving the crucial problems of goal implementation. Thereafter, we will ask whether implementation intentions foster goal attainment even under conditions that are commonly viewed as not amenable to self-regulation attempts, such as succeeding on an intelligence test or overcoming spider phobia. Finally, we will report research showing that implementation intentions can even foster goal-striving in those samples (e.g., children with ADHD) that are known to suffer from impaired action control.

Keywords: Implementation intentions, Goal intentions, Medial/lateral pre-frontal cortex, Action Initiation, Goal shielding, Disengagement, Overextension, Academic test performance, Negotiation performance, Winning competitions, Overcoming habitual responses, Simon effect, Spider phobia, Weapon identification task, Behavior change interventions, Children with ADHD, Response inhibition, Delay of gratification, Set-shifting, Multi-tasking

Research on self-regulation and self-control has defined its object of interest by emphasizing different phenomena and processes. The many targeted phenomena include overriding unwanted thoughts (e.g., related to distractions, temptations, stereotyping, self-inflation), feelings (e.g, anger, disgust, fear, sadness, prejudice) and behaviors (e.g., aggressive, immoral, risky, health-damaging, underachieving). The various processes that are assumed to promote self-regulation and self-control pertain to fostering the wanted over the unwanted by cognitively inhibiting the unwanted and/or activating the wanted, or by modifying one's current or anticipated emotions so that the wanted can be executed more easily, and the unwanted can be more easily halted or prevented. Often it is assumed that effective self-regulation and self- 
control requires a switch; for instance, a switch from a hot mode of information processing to a cool mode, from a low-level to a high-level construal, a short-term to a long-term time perspective, from impulsive to reflective action control, from habitual bottom-up direct action control by present stimuli to top-down control by the desired end states specified in respective goals, or from low-priority/low-importance goals to high-priority/high-importance goals. It is this latter process of achieving self-regulation and self-control by striving for goals that is focused on in the present chapter. We will argue that goal attainment is facilitated when people plan out their goal-striving in advance. More specifically, we suggest that effectively regulating one's goal-striving by making if-then plans (i.e., form implementation intentions) is a reliable and powerful way to achieving self-control.

\section{Implementation Intentions: Planning OUt Goal-Striving in AdVANCE}

To form an implementation intention (Gollwitzer, 1993, 1999), one needs to identify a future goalrelevant situational cue (i.e., the if-component) and a related planned response to that cue (i.e., the then-component). Whereas a goal intention specifies the desired event in the form of "I intend to perform Behavior X/to reach Outcome X" (e.g., to exercise regularly/ to get an $A$ in Introductory Psychology), an implementation intention specifies both an anticipated goal-relevant situation and a proper goal-directed response. Thus, an implementation intention that serves the goal intention to "get an A in the social psychology class" would follow the form "If Situation $Y$ arises (e.g., when my roommates will be asking me to go out tonight), then I will perform Behavior $Z$ (e.g., will say that $I$ will be joining them next week when my exam is over)."

There is added benefit of an implementation intention: a meta-analysis by Gollwitzer and Sheeran (2006) involving over 8,000 participants in 94 independent studies reported an effect size of $d=0.65$. This medium-to-large effect size (Cohen, 1992) represents the additional facilitation of goal achievement by implementation intentions compared to goal intentions alone. As goal intentions by themselves already have a facilitating effect on behavior enactment (Webb \& Sheeran, 2006), the size of this effect is remarkable.

\section{How Do Implementation Intention Effects Come About?}

The mental links created by implementation intentions facilitate goal attainment on the basis of psychological processes that relate to both the anticipated situation (the "if" part of the plan) and the intended behavior (the "then" part of the plan). Because forming an implementation intention implies the selection of a critical future situation, the mental representation of this situation becomes highly activated, and hence more accessible (Gollwitzer, 1999). This heightened accessibility of the "if" part of the plan was observed in several studies (e.g., Aarts, Dijksterhuis, \& Midden, 1999; ParksStamm, Gollwitzer, \& Oettingen, 2007; Webb \& Sheeran, 2007, 2008) and means that people are in a good position to identify and take notice of the critical situation when they subsequently encounter it (e.g., Webb \& Sheeran, 2004).

Studies also indicate that implementation intentions forge a strong association between the specified opportunity and the specified response (Webb \& Sheeran, 2007, 2008). The upshot of these strong links is that the initiation of the goal-directed response specified in the if-then plan becomes automated-that is, exhibits features of automaticity including immediacy, effciency, and redundancy of conscious intent. The idea is that people do not have to deliberate any more about when and how they should act when they have formed an implementation intentionunlike people who have formed mere goal intentions. Evidence that if-then planners act quickly (Gollwitzer \& Brandstätter, 1997, Experiment 3), deal effectively with cognitive demands (Brand: stätter, Lengfelder, \& Gollwitzer, 2001), and do not need to consciously intend to act at the crit ical moment (Bayer, Achtziger, Gollwitzer, \& Moskowitz, 2009; Sheeran, Webb, \& Gollwitzer, 2005 , Study 2) is consistent with this idea.

These component processes of implemen tation intentions (enhanced cue accessibility. 
atomatization of responding) mean that ifViren planning enables people to see and seize rod opportunities to move towards their goals. Thastoning an if-then plan thus strategically attomates goal-striving (Gollwitzer \& Schaal, (998) because people delegate control of goaldrected behaviors to pre-selected situational ties with the explicit purpose of reaching their goals, that is, automatic action initiation orginates in a conscious act of will (if-then blaming).

\section{Implementation Intentions and overcoming Problems of Goal-Striving}

Given these special features of action control by implementation intentions, one wonders whether people benefit from forming implementation intentions when goals geared at showing a high amount of self-control or selfdiscipline are at stake. Let us discuss this question by addressing the four central problems of goal realization.

\section{Getting started}

Numerous studies suggest that problems of getting started on one's goals can be solved effectively by forming implementation intentions. For example, Gollwitzer and Brandstätter (1997, Study 2) analyzed a goal intention (i.e., writing a promised report about how one spent Christmas Eve) that had to be performed at a time (i.e., during the subsequent Christmas holiday) where people are commonly busy with other things. Still, research participants who had furnished their goal intention with an implementation intention that specified when, where, and how one wanted to get started on this project were about three times as likely to actually keep their promise to write the report than mere goal intention participants. Similarly, Oettingen, Hönig, and Gollwitzer (2000, Study 3) observed that implementation intentions helped college students to act on their goal to regularly practice solving certain math problems (e.g., at 10 a.m. in the morning of every Wednesday over the next 4 weeks).

Other studies have examined the ability of implementation intentions to foster goal- striving that is somewhat unpleasant to perform and thus are associated with an initial reluctance to act. For instance, the goal to perform regular breast examinations (Orbell, Hodgkins, \& Sheeran, 1997) or cervical cancer screenings (Sheeran \& Orbell, 2000), resume functional activity after joint replacement surgery (Orbell \& Sheeran, 2000), eat a low-fat diet (Armitage, 2004), recycle (Holland, Aarts, \& Langendam, 2006), and engage in physical exercise (Milne, Orbell, \& Sheeran, 2002), were all more readily acted upon when people had furnished these goals with implementation intentions.

\section{Staying on Track}

Many goals cannot be accomplished by simple discrete one-shot actions but require that people keep striving for the goal over an extended period of time. Such staying on track may get very difficult when certain internal (e.g., being anxious, tired, overburdened) or external stimuli (e.g, temptations, distractions) are not conducive to goal realization but instead generate interferences that could potentially derail the ongoing goal pursuit. Implementation intentions can facilitate the shielding of such goal pursuits from the negative influences of interferences from outside the person by suppressing these negative influences (Gollwitzer \& Schaal, 1998). For example, if a person wants to avoid being unfriendly to a friend who is known to make outrageous requests, she can protect herself from showing the unwanted unfriendly response by forming suppression-oriented implementation intentions. Such suppressionoriented implementation intentions may take various forms: "And if my friend approaches me with an outrageous request, then I will not respond in an unfriendly manner!" or "..., then I will respond in a friendly manner!" or "..., then I'll ignore it!"

But suppression-oriented implementation intentions can also be used to shield ongoing goal pursuits from disruptive inner states. Achtziger, Gollwitzer, and Sheeran (2008, Study 1) report a field experiment concerned with dieting in which goal shielding was supported by suppression implementation intentions geared at controlling potentially interfering inner states 
(i.e., cravings for junk food). An alternative way of using implementation intentions to protect ongoing goal-striving from getting derailed by adverse inner states (e.g., inappropriate moods, ego-depletion, irritation) is forming implementation intentions geared at stabilizing the ongoing goal pursuit at hand (Bayer, Gollwitzer, \& Achtziger, in press). Using again the example of a person who is approached by her friend with an outrageous request, let us assume that this person is also tired or irritated and thus particularly likely to respond in an unfriendly manner. If this person has stipulated in advance in an implementation intention what she will converse about with her friend, the critical interaction may simply run off as planned, and being tired or irritated should fail to affect the person's goal to relate to her friend in a civilized manner.

\section{Calling a Halt}

The self-regulatory problem of calling a halt to a faulty goal pursuit can also be ameliorated by forming implementation intentions. People often fail to readily disengage from chosen means and goals that turn out to be faulty because of a strong self-justification motive (Brockner, 1992). Such escalation phenomena (also referred to as "throwing good money after bad") can be controlled effectively, however, by the use of implementation intentions that specify exactly when and how to consider a switch to a different means or a different goal. For instance, Henderson, Gollwitzer, and Oettingen (2007) asked participants who had chosen a certain strategy for a given task goal to either form an implementation intention that specified a complex reflection response ("If I receive disappointing feedback, then I'll think about how things have been going with my strategy!") or a more simple action response ("If I receive disappointing feedback, then I'll switch my strategy!"), or merely set the goal to always use the best strategy available. Henderson et al. observed that action implementation intentions facilitated disengagement as a response to experienced failure no matter whether there were signs that things were picking up or that they would continue to stay bleak. Reflection implementation intention participants, on the other hand, integrated information about recent improvement in forming their disengagement decision (i.e., they were less willing to disengage when things were picking up). This study shows that implementation intentions can be used to control the costly escalation of behavioral commitment commonly observed when people experience failure with a chosen strategy of goal striving. Using reflection implementation intentions (as compared to action implementation intentions) even allows for flexible disengagement in the sense that recent turns to the better are respected in one's decision to switch (or not) to a different goal-striving strategy.

\section{Not Overextending Oneself}

The assumption that implementation intentions subject behavior to the direct control of situational cues (Gollwitzer, 1993) implies that the self is not implicated when behavior is controlled via implementation intentions. As a consequence, the self should not become depleted (Muraven \& Baumeister, 2000) when task performance is regulated by implementation intentions, and thus for individuals using implementation intentions, not over-extending themselves should become easier. Indeed, using different ego-depletion paradigms, research participants who had used implementation intentions to self-regulate in a first task do not show reduced self-regulatory capacity in a sub. sequent task. Whether the initial self-regulation task was controlling emotions while watching a humorous movie (Gollwitzer \& Bayer, 2000), or performing a Stroop task (Webb \& Sheeran, 2003, Study 1), implementation intentions suc cessfully preserved self-regulatory resources as demonstrated by greater persistence on sub sequent difficult tasks (i.e., solving difficult anagrams).

\section{When the Going Gets Tough: IMPLEMENTATION INTENTION EFFECTS IN THE FACE OF HARDSHIPS}

In the rest of the chapter we will explore whether implementation intention unveil their beneficial effects even under conditions where 
golstriving becomes tough. This question and tie respective line of research have been stimilated by Aristotle's concept of akrasia (lack of 6ill power). We felt that any strategy of goalsituing that psychology claims to contribute topeople's self-control has to prove itself under conditions where people commonly fail to demonstrate willpower. Such conditions are manifold and thus we concentrated on the following four (a) situations in which a person's knowlcdge and skills constrain performance (such as taking academic tests); (b) situations in which an opponent's behavior limit one's performance (such as sports competitions or negotiation settings); (c) situations in which the wanted behavioral (e.g., no littering), emotional (e.g., no fear), or cognitive (e.g., no stereotyping) response runs into conflict with habits favoring an antagonistic response; and (d) situations in which individuals who are known to have problems with action control, such as children with ADHD, have to tackle the typical problems burdening goal-striving (e.g., shielding ongoing goal-striving from distractions).

\section{Academic Test Performance}

Performance on academic tests (math tests, general intelligence tests) is by definition determined primarily by a person's knowledge, analytic capability, and cognitive skills. To increase test scores by willpower, a person thus may want to focus on motivational issues such as staying concentrated on the various test items throughout the test or by reducing worry cognitions (e.g., Did I find the right answer on the last item?) and self-doubts (e.g., Do I have the slcills to find the right solution for the item at hand?).

\section{Taking a Math Test}

Bayer and Gollwitzer (2007, Study 1) asked female high school students to complete a math test (composed by high school math teachers) under two different instructions. Half of the participants were asked to form the mere achievement goal intention: "I will correctly solve as many tasks as possible!" The other half of the participants had to furnish this goal intention with the following self-efficacy-strengthening implementation intention "And if I start a new task, then I will tell myself: I can solve this task!" We observed that participants in the implementation intention group showed a better performance in the math test (in terms of number of tasks solved correctly) than participants in the mere goal intention condition, indicating that self-efficacy-strengthening implementation intentions facilitate successful goal-striving in a challenging achievement situation.

Implementation intentions are usually constructed by specifying a situational cue in the if-part and linking it to goal-directed cognitive or behavioral responses in the then-part. In the present study, a critical situational cue (i.e., starting a new test item) in the if-part was linked to a motivational response (i.e., a private selfefficacy strengthening statement) in the thenpart. Interestingly, this pre-programmed, inner self-motivating speech sufficed to produce better test performance. This suggests that implementation intentions can be used to ameliorate also motivational problems of goal implementation (such as self-doubts in the face of challenging test items) and thus increase a person's willpower (i.e., the potential to exert self-control).

The present manipulation to increase willpower was particularly parsimonious, as we only had participants asked to form a plan in respect to when they will have to execute an inner self-efficacy strengthening statement. Still, these findings leave open a pressing question: Does this inner speech need to take the format of an implementation intention? Maybe it suffices that participants simply form an additional goal intention geared towards holding up self-efficacy, such as "And I will tell myself: $I$ can solve these problems!" To explore this possibility, Bayer and Gollwitzer (2007) conducted a follow-up study in which participants had to take an intelligence test; this study included a further control condition (i.e., a self-efficacy-strengthening goal intention condition).

\section{Taking an Intelligence Test}

Bayer and Gollwritzer (2007, Study 2) asked college students to perform the Raven's Advanced Progressive Matrices intelligence test. They found that students who had been asked to 
form a self-efficacy-enhancing implementation intention showed higher test performance than participants with a mere goal intention to perform well. This replication of the implementation intention effect observed with high school students working on a math test is particularly noteworthy as the well-established Raven's Advanced Progressive Matrices intelligence test (Raven, 2000) was used. The tasks on the test get increasingly harder requiring greater cognitive capacity to encode, analyze, and solve them correctly; the test is considered to allow for reliable assessments of a person's analytical reasoning capabilities.

In this study, it was also examined whether adding a self-efficacy-strengthening goal intention ("And I will tell myself: I can do these problems!") to the achievement goal intention ("I will correctly solve as many tasks as possible!") improves participants' test performance. As it turned out, test performance improved only when participants were instructed to form additional self-efficacy strengthening implementation intentions. This finding is important for several reasons. First, many of the field and laboratory studies investigating the benefits of implementation intentions (e.g., on health behaviors, job safety, environment protection; see meta-analysis by Gollwitzer \& Sheeran, 2006) do not use an additional condition that spells out the "then" part of the implementation intention in terms of a further goal intention (for an exception, see Oettingen, Hönig, \& Gollwitzer, 2001). Therefore, in these studies the benefits of implementation intentions as compared to mere goal intentions could potentially be based on having access to additional information on how to act. With the present study, we can rule out this alternative account as the use of the strategy of strengthening one's selfefficacy in terms of forming a mere goal intention did not lead to higher test scores. Only when this strategy was suggested to participants in the format of an if-then plan, positive effects on test performance emerged.

Finally, the observed differences between selfefficacy-strengthening implementation intentions and self-efficacy-strengthening goal intentions further support the assumption (Gollwitzer, 1999) that implementation intentions-by specifying situational cues-recruit different action control processes than goal intentions. Whereas the latter are said to instigate effortful, conscious processes, the former trigger automatic processes. Assuming that performing the Raven test is quite demand. ing and thus burdens cognitive capacities, it is not surprising that only self-efficacy-strengthening implementation managed to be effective.

\section{Dealing With Opponents}

Often our performances are restrained by others who are competing with us for positive outcomes. Typical examples are sports competitions where athletes try to triumph over their opponents or negotiations in which a common good has to be shared between two opposing parties. In such situations, exerting willpower means to effectively protect one's goal-striving from unwanted influences of the competitive situation. In the following, we report two studies showing that implementation intentions can be used to bolster such willpower.

\section{Winning Tennis Competitions}

Studies on sports competitions discovered that negative inner states (e.g., performance anx. iety, Covassin \& Pero, 2004; anger, Wughalter \& Gondola, 1991; feelings of stress, Hanegby \& Tenenbaum, 2001) hamper the quality of athletic performance. This is particularly true for sports that involve a direct competition with an oppo nent as it is the case with tennis. Accordingly. Achtziger, Gollwitzer, and Sheeran (2008,Study 2) wondered whether specifying these negative inner states as critical cues in the "if" compo nent of implementation intentions and a gode shielding response in the "then" component supports staying on track under such adverse inner states. The specified goal-shidiling responses were taken from research that and lyzed strategies of improving one's performaile during a tennis match (e.g, ignoring the noise made by the audience, focusing one's attentifit on the ball, engaging in relaxation behaviorse Anshel \& Anderson, 2002).

Achtziger et al. manipulated participants goal intention to perform well in a tennis niate 
Wher than simply measuring it. Accordingly, the had a no-goal control condition and a mere 6ilintention condition in which tennis playot (faken from German tennis leagues) were assigned the following goal the day before a offical match: "I will play each ball with utmost concentration and effort to win the match!" 11. the implementation intention condition, participants were also assigned this goal, and In addition, asked to form four if-then plans that specified internal states in the "if" components (e.g., performance anxiety, physiological arousal) and staying-on-track responses in the then". components (e.g., ignoring the adverse inter state). It was observed that self- and otherratings (by trainers and teammates) of physical fitness and performance were higher for implementation intention participants as compared to both goal intention and no-goal (control) participants.

This field experiment is one of the few implementation intention studies (e.g., Murgraff et al., 1996) in which participants could choose their implementation intentions in an individualized manner and make use of more than just one implementation intention. Participants selected the four, most personally relevant, negative inner states as "if" components of their implementation intentions and the four goal-directed responses that they assessed as being suited best for shielding their goal-striving as "then" components. These findings speak to the idea that implementation intention inductions can easily be tailored to one's particular self-regulatory problems at hand. To facilitate goal-striving and increase rates of goal attainment in competitive situations, people apparently can also form multiple if-then plans, geared at alleviating the particular inner states they find most detrimental to their performance, and linking them to goal-directed responses they perceive as most useful (instrumental).

Moreover, in the present study the goaldirected responses specified in the then-component of the implementation intentions studied were coping responses linked to various handicaps and weaknesses originating inside the person and not to challenges arising from outside the person. One therefore may wonder whether if-then plans that link coping responses to disruptive external events will also be effective in shielding an ongoing goal pursuit. Research by Gollwitzer and Schaal (1998) on resistance to temptations provides an affirmative answer to this question, given that certain coping responses are specified in the "then" component (e.g., ignore responses). Participants who had to perform tedious arithmetic problems for a period of 15 minutes were more successful in doing so despite the presentation of various interspersed attractive video clips, when participants had formed implementation intentions that specified "attractive video clips" in the "if" component and an "ignore" response in the "then" component.

Reflecting on the pros and cons of forming implementation intentions that link a coping response to negative external events versus det rimental inner states, the following should be kept in mind: specifying inner states has the advantage that these detrimental states could function as a summary label for all of those negative external events that might compromise goal-striving - even those one is not aware of or may fail to anticipate. Accordingly, whenever a person is not in a good position to know about and anticipate critical events, specifying detrimental inner states seems to be the safer strat egy to shield one's goal-striving. For instance, patients with panic attacks are usually not aware of which kinds of external events trigger the attack and whether these events are to be expected in a forthcoming external context (e.g., Hinton, Nathan, \& Bird, 2002). For these patients it would make sense to specify inner states (i.e., upcoming anxiety) as "if" components to control their negative emotions.

\section{Prevailing in Loss Framed Negotiations}

Negotiations particularly lend themselves well to investigate the power of implementation intentions: Negotiations are cognitively very demanding tasks in which a large amount of information has to be processed online, and the course of events is hard to predict as one is not performing a task alone but conjointly with an opponent. Thus, negotiations can be understood as the prototype of a complex situation 
in which striving for desired goals can easilyr become derailed. Therefore, analyzing whether the beneficial effects of implementation intentions found in previous research also hold true in negotiations is of great interest to assess whether needed willpower accrues from forming if-then planning.

In their negotiation research, Trötschel and Gollwitzer (2007) explored whether the selfregulation strategy of forming implementation intentions allows negotiators to arrive at high performance levels in finding agreements even if they have to operate under the adverse conditions of a loss frame (i.e., the negotiation outcomes are loss-framed and thus a resistance to concession making is induced; e.g., Bottom \& Studt, 1993; Olekalns, 1997). In one of their experiments, pairs of negotiators were assigned the role of representatives of two neighboring countries (i.e., the blue and the orange nations) and asked to negotiate the distribution of a disputed island (i.e., its regions, villages, and towns). One group of pairs of negotiators was asked to form the mere pro-social goal of "I want to cooperate with my counterpart?", and a second group to furnish this goal with a respective implementation intention: "And if I receive a proposal on how to share the island, then I will make a cooperative counterproposal!" Both groups were then subjected to a frame manipulation, whereby both members of the pair received a loss-frame manipulation (i.e., each region's value was expressed in points that are lost when the region is given away). In addition, two control conditions were estab. lished: A first control condition contained pairs of negotiators who were not assigned pro-social goals and asked to negotiate under a loss frame; the second control condition also consisted of pairs of negotiators who were not assigned prosocial goals, but these pairs of negotiators were asked to negotiate under a gain frame (i.e., each region's value was expressed in points that are won when the region is kept). These two control conditions were used to establish the negative influence of loss versus gain frames on joint profits. In addition, the loss-frame control condition served as a comparison group for the two critical experimental groups (i.e., the pro-social goal group and the pro social goal plus implementation intention group).

When looking at the agreements achieved (i.e., level of joint outcomes), it was observed that pairs of loss-frame negotiators with a pro-social goal intention managed to somewhat reduce the resistance to concession making arising from the loss-frame negotiation context, but that only negotiators who furnished their pro-social goal intentions with respective implementation intentions were successful in completely abolishing the negative impact of the loss-frame negotiation context (i.e., showed a negotiation performance that was not different from that of gain-frame negotiators). In addition, action control via implementation intentions was found to be very efficient (i.e., implementation intentions abolished the negative effects of loss framing by leaving the negotiators' cognitive capacity in tact); negotiators who had formed implementation intentions were more likely to use the cognitively demanding integrative negotiation strategy of logrolling (i.e., making greater concessions on low rather than high priority issues).

In a follow-up experiment, the effects of pro-social goals and respective implementation intentions on the course of the negotiation were analyzed. The analyses on the course of the negd. tiation indicated that loss-frame pairs of negotiators who had furnished their pro-social goals with corresponding implementation intentions revealed a steeper progress in finding agreements than loss-frame pairs of negotiators without pro: social if-then plans; actually, at the end of the negotiation implementation intention, particl pants had achieved negotiation agreements that were comparable to those of gain-frame pairs of negotiators. Furthermore, implementation inten tions were again strongly associated with using the integrative negotiation strategy of logrolling: Apparently, having one's negotiation behavior controlled by implementation intentions sared cognitive resources that could be used to sucess? fully discover integrative solutions.

\section{Overcoming Habitual Responses}

The self-regulation of one's goal-striving becomes difficult when habitual resporst 
thict with initiating and executing the needed 601 lirected responses instrumental to goal titanment. In such cases, having willpower ineans to assert one's will of attaining the chosen 60il against one's "bad" habits. Accordingly, we wordered whether the self-regulation strategy of forming if-then plans can help people to let their cols win out over their habits.

\section{tehavioral Responses}

Vy assuming that action control by implemenation intentions is immediate and efficient, and topting a simple horse race model of action control people can be expected to be in a position to brak habitualized responses by forming implementation intentions (i.e., if - then plans that spell oit a response that is contrary to the habitualtred response to the critical situation). Such studTes have been conducted successfully in the field (Holland, Aarts, \& Langendam, 2006), but also In the laboratory (Cohen et al., 2008, Study 2).

Holland, Aarts, and Langendam (2006) addtessed whether implementation intentions could help break unwanted habits (and replace them with new wanted behaviors) in a field experiment conducted in an institution. The goal of the researchers was to increase the use of recycling bins for plastic cups and paper, and reduce the bad habit of throwing out these recyclable items in personal wastebaskets. Participants were randomly assigned to one of six conditions: a no-treatment control condition, a control condition with a behavior report questionnaire, a facility condition where each participant received her own recycle bin, a combined facility and questionnaire condition, and two implementation intention conditions: one with a personal facility, and one without. Recycling behavior was substantially improved in the facility as well as in the implementation intentions conditions in Week 1 and Week 2, and still two months after the manipulation. In addition, the correlation between past and future behavior was strong in the control conditions, whereas these correlations were nonsignificant and close to zero in the implementation intention conditions. Apparently, implementation intentions effectively broke old habits by facilitating new recycling behavior. This shows that even strongly habitualized behaviors can be replaced by newly planned goal-directed behaviors via implementation intentions.

Cohen et al. (2008, Study 2) explored the suppression of habitual responses in a more controlled laboratory experiment using the Simon task. In this paradigm, participants are asked to respond to a non-spatial aspect of a stimulus (i.e., whether a presented tone is high or low) by pressing a left or right key, and to ignore the location of the stimulus (i.e., whether it is presented on one's left or on the right side). The difficulty of this task is in ignoring the spatial location (left or right) of the tone in one's classification response (i.e., pressing a left or right response key; Simon, 1990). The cost in reaction times is seen when the location of the tone (e.g., right) and required key press (e.g., left) are incongruent, as people habitually respond to stimuli presented at the right or left side with the corresponding hand. Cohen et al. (2008, Study 2) found that implementation intentions eliminated the Simon effect for the stimulus that was specified in the "if" component of the implementation intention. Reaction times for this stimulus did not differ between the congruent and incongruent trials (i.e., they were fast throughout).

\section{Emotional Responses}

Recent research has also explored whether adding implementation intentions to emotion-regulation goals would make these goals more effective (Schweiger et al., 2009). In one study, participants were exposed to a series of pictures used to elicit disgust. When participants formed a response-focused implementation intention ("If I see disgusting scenes, then I'll stay calm and relaxed."), they exhibited a reduction in arousal compared to a control group. As anticipated, participants who operated on mere goals to not get disgusted could not willfully reduce their arousal to the disgusting pictures. A second study analyzed the control of spider fear in spider phobics. Both participants with response-focused implementation intentions ("If a see a spider, then I will stay calm and relaxed.") and antecedentfocused implementation intentions ("If I see 
a spider, then I'll ignore it.") experienced less negative affect in the face of spider pictures than a no self-regulation control group; again, mere goal intentions to not get frightened failed to achieve this effect. Moreover, spider phobics using implementation intentions even managed to control their fear to the low level observed with a sample of participants who were pre-selected on the basis of having no fear of spiders at all.

In a final study using dense-array electroencephalography (EEG) to assess event-related potentials (ERPs), the effectiveness of ignoreimplementation intentions for the control of spider fear in spider phobics was replicated. More important, participants who added ignore-implementation intentions to their goal intentions to not get frightened showed a lower positivity in the P1 (an ERP assessed around $120 \mathrm{~ms}$ after stimulus presentation in the occipital and parietal brain areas) when detecting spider pictures as compared to mere goal and control participants; no such difference was found for pleasant or neutral control pictures. Indeed, previous research has shown that the P1 can discriminate high-arousing negative stimuli from neutral and positive stimuli (Smith et al., 2003), as well as spiders from nonthreatening animals such as butterflies (Carretie et al., 2003). In line with these findings, participants in our study without any emotion-regulation goal intention (control condition) or those with a mere goal intention showed the typical positivity of the P1 at about $120 \mathrm{~ms}$ when detecting threatening stimuli. In contrast, forming an implementation intention led to a down-modulation of this component, resulting in a significantly lower positivity of the P1. This attests to the specificity of the implementation intention effect, and again supports our assumption that forming implementation intentions leads to strategic automation of the goal-directed responses specified in their "then" part, as conscious efforts to inhibit the activation of the mental representation of a presented stimulus are commonly assumed to show their effects later than $300 \mathrm{~ms}$ after stimulus presentation (overview by Bargh \& Chartrand, 2000).

\section{Cognitive Responses}

Automatic cognitive biases such as stereotyping represent another type of habitualized response that can be in opposition to one's goals. Although one may have the goal to be egalitarian, automatic stereotyping happens quickly and unintentionally; some attempts to control automatic stereotyping have even resulted in backfire effects. Extending earlier work by Gollwitzer and Schaal (1997), Stewart and Payne (2007) examined whether implementation intentions designed to counter automatic stereotypes (e.g." When I see a Black face, I will then think "safe." ") could reduce stereotyping towards a category of individuals (versus a single exemplar). They used the Process Dissociation Procedure (PDP; Jacoby, 1991) to estimate whether the reduction in automatic stereotyping came about by reducing automatic stereotyping, increasing control, or a combination of these two processes. It was found that implementation intentions reduced stereotyp ing in a weapon identification task (Studies 1 and 2) and an IAT task (Study 3) by reducing automatic effects of the stereotype (without increasing conscious control). This reductionin automatic race bias held for even new members of the category (Study 2). These studies sugget that implementation intentions are an efficient way to overcome automatic stereotyping.

\section{Implications: Implementation Intentions in} the Brain

The reported research findings on the contro of habitual responses by implementation inter tions implies that action control by if-then plan turns top-down control by goals into bottomu. control by the situational cues specified in "if" component of an implementation int tion. This implication was recently tested int MRI study by Gilbert et al. (2009). The stu draws on the gateway hypothesis of rostralpis frontal cortex (area 10) function by Burge Simons, Dumontheil, and Gilbert (2005) gesting a distinction between action con that is primarily triggered by low level sti lus input, and action control that is prim guided by higher-level goal representa 
Witig at the results of a host of studies using Voffent kinds of executive function tasks, - ves set al. observed in a meta-analysis that intulus driven, bottom-up action control is soclated with medial area 10 activity, whereas driven, top-down action control is associted with lateral area 10 activity. Accordingly, 6libert et al. (2009) postulated that action ontrol by implementation intentions should 1). characterized by medial area 10 activity, Whereas action control by mere goals should be associated with lateral area 10 activity.

To test this hypothesis, a prospective memof (PM) paradigm was used. Prospective nemory tasks require participants to perform an ongoing task (e.g., a lexical decision task, d (lassification task), but remember to also Werform an additional response (i.e., the PM tesponse, e.g., pressing the space bar) whenever a particular stimulus is presented within the ongoing task (e.g., a particular word, a particutar constellation of the stimuli to be classified). In the Gilbert et al. study, each participant had to perform two different prospective memory tasks, one with a goal intention to perform the PM responses and the other with an implementation intention to perform these responses. As it turned out, implementation intentions facilitated the performance of PM responses as compared to mere goal intentions, and this gain in performance did not lead to any additional costs in performing the ongoing task. Even more importantly, PM performance based on a goal intention were accompanied by greater lateral area 10 activity, whereas PM performances based on implementation intentions were associated with greater activity in the medial area 10. Moreover; the difference in brain activity associated with correctly responding to PM targets under goal vs. implementation intentions correlated strongly and significantly with the behavioral difference as a consequence of acting on the basis of goal versus implementation intentions. The fact that acting on implementation intentions is associated with medial area 10 activity, whereas acting on goal intentions is associated with lateral area 10 activity, adds further support to the theory that by forming implementation intentions, people can switch from goal-striving that is guided by conscious top-down control to direct, stimulus-triggered goal-striving (Gollwitzer, 1999).

\section{Critical Samples: Children with Attention- Deficit/Hyperactivity-Disorder (ADHD)}

In the past, implementation intention research with clinical samples has been conducted to test process hypotheses on how implementation intentions achieve their effects. For instance, the hypothesis that implementation intentions lead to efficient action control (i.e., action control by implementation intentions does not suffer from cognitive load) was tested by assessing whether heroine addicts during withdrawal, patients suffering from schizophrenia (Brandstätter, Lengfelder, \& Gollwitzer, 2001, Studies 1 and 2), and patients with a frontal lobe damage (Lengfelder \& Gollwitzer, 2001) also benefit from forming implementation intentions. The present line of research on children with ADHD instead serves the purpose of testing the power of implementations in terms of improving goal-striving even under adverse conditions. Children with ADHD are known to be inattentive, hyperactive, and particularly impulsive (APA, 1994). They show impairments in focusing, sustaining, and switching attention, as well as inappropriate motor activity, and limited inhibitory control of responses (e.g., Barkley, 1997; Nigg, 2001). ADHD emerges in the preschool years and affects $3 \%$ to $5 \%$ of school-aged children.

Approximately two-thirds $(50 \%-70 \%)$ of individuals diagnosed with ADHD exhibit comorbid clinical problems related to learning ability, social adjustment and functioning, and/or emotional well-being. ADHD-related symptoms, as well as comorbid symptoms, lead to several difficulties in everyday life. Children with ADHD show moderate to large deficits in academic achievement (Frazier et al., 2007) and experience interpersonal problems (Hoza et al., 2005). Consequently, in comparison to children without $A D H D$, children with ADHD tend to receive poorer grades in school, more frequently need to repeat a school year, often require tutoring or placement in special classes, and show 
reading disabilities. Furthermore, in comparison to children without ADHD, children with ADHD are less popular with their peers, more frequently experience rejection, and are less likely to have dyadic friendships.

ADHD not only leads to difficulties in everyday life, but also to impaired performance on different neuropsychological tasks measuring inhibitory control (Halperin \& Schulz, 2006), such as the Go/NoGo task (Rubia et al., 2001), the Continuous Performance Test (CPT; Rosvold et al., 1956), the Stop Signal Test (SST; Logan \& Cowan, 1984), and the Stroop Test (Stroop, 1935). For example, in a Go/NoGo task, a response must be either executed or inhibited in response to the presentation of a Go or a NoGo signal, respectively. In most studies using the Go/NoGo paradigm, the inhibitory effect is enhanced with a predominant Go response resulting from frequent Go trials and infrequent NoGo trials. Generally, children with $\mathrm{ADHD}$ have longer response times to Go stimuli (i.e., targets) and make more errors when presented with NoGo stimuli (i.e., nontargets).The basic paradign in a CPT is typically a Go/NoGo task in which the participant responds to the presentation of a target and withholds the response to the presentation of a non-target. Importantly, CPT derived measures predict the presence of most ADHD symptoms (Epstein, Erkanli, \& Conners, 2003): Children with ADHD miss more targets and show more false alarms to nontargets than children without ADHD. Unlike the Go/NoGo task and the CPT, the SST requires children to inhibit a motor response while the action is being executed. Furthermore, research illustrates that children with ADHD have slower stop signal reaction times and significantly slower reaction times in Go trials than comparison children without ADHD on the SST (e.g, Oosterlaan, Logan, \& Sergeant, 1998). Finally, in a Stroop Interference Test (Stroop, 1935) participants have to name the color (e.g., green) of a noncongruent color word (e.g., red). Participants must inhibit the automatic response (i.e., reading) in favor of the non-automatic response (i.e., naming the color). In a meta-analysis, Homack and Riccio (2004) showed that children with ADHD consistently exhibit poorer performance on Stroop Tasks when compared to children without ADHD. In sum, these findings support the idea that behav. ioral inhibition is a core deficit in children with ADHD.

Children with ADHD also have difficulties on tasks requiring cognitive flexibility (i.e., shifting a cognitive set). For example, on the Wisconsin Card Sorting Test (WCST; Berg, 1948), children with ADHD tend to preserve instead of respond flexibly (i.e., they stick to unsuccessful hypotheses instead of adapting their strategy). Accordingly, this tendency appears to be another characteristic feature of ADHD, explaining these children's poorer performances on various dependent variables measured with the WCST. Moreover, children with ADHD also have difficulties in multitasking. The Six Elements Test, for example, which mea sures complex planning behavior in the sense of multitasking situations, requires the simul. taneous execution of six different tasks (SET, Burgess, 2000). Teenagers with ADHD show significantly worse results on the SET than chil dren without ADHD (Clarke, Prior, \& Kinsella, 2000). In sum, these findings seem to suggest that children with ADHD have a host of diff culties in regulating their own behavior.

\section{Implementation Intentions facilitate Response Inhibition in Children with ADHD}

Our initial research investigated whether impl ementation intentions can support children with ADHD on a Go/NoGo task. The task required children to both classify random ized stimuli presented on a computer screen as well as inhibit classification in response to a NoGo signal (Gawrilow \& Gollwitzer, 2008). Specifically, children had to respond as quidfy as possible to pictures of vehicles or animals by pressing a respective vehicle or animal key (If) Go trial). On one third of the trials, however an audible NoGo signal presented before to stimulus announced to the children that they should inhibit their response on that tral 16 NoGo trial). In two experiments, children with ADHD were assigned to either a goal intention group ("I will not press a key for picturestth have a sound!") or an implementation intento 
1.t. And if I hear a tone, then I will not press G) (key!') Both the response times for the Go 14 Is and the number of successful stops on the No6o trials were measured.

In the first study, the performances of childien with and without ADHD were compared. Gifdren with $\mathrm{ADHD}$ who furnished a supirssion goal with implementation intentions inproved inhibition of an unwanted response on Go/NoGo task to the same level observed thothildren without ADHD. The second study compared the performances of children with WHO with and without psychostimulant nedication. In this study, a combination of inplementation intentions and psychostimulain medication resulted in the highest level of suppression performance in children with ADHD (Gawrilow \& Gollwitzer, 2008, Studies and 2).

In a recent follow-up study, Gawrilow, Oettingen, and Gollwitzer (2009a, Study 1) asked children with and without ADHD to complete - Number-Stroop task. All children saw rows of single-digit numbers containing numbers from 1 to 9 on a computer screen. The amount of numbers on each trial was varied from two to seven. The task required children to either name the number in a naming task (e.g., press key "one" to a row of four ones) or count the amount of numbers in a counting task (e.g., press key "four" to a row of four ones). All children began with the (easier) naming task, followed by the (more difficult) counting task. Error rates and response times were measured as dependent variables.

To establish the three experimental conditions, prior to the counting task one third of the children received only a goal intention ("I will count the numbers."), while the remaining children additionally received one of two different implementation intentions: a task-facilitating implementation intention (e.g., "As soon as a new row of numbers is presented, I will concentrate on the amount of numbers.") or a distraction-inhibiting implementation intention (e.g., "As soon as a new row of numbers is presented, I will ignore the type of the numbers.").

Whereas children with and without ADHD both profited from if-then plans, children with and without ADHD had an increase in errors on the counting task. This occurred despite having the explicit goal to count the numbers. Only when given an additional implementation intention did they manage to nearly remain at the same error level in the counting task as in the naming task. In line with research by Mischel and colleagues (e.g., Patterson \& Mischel, 1976) both children with and without ADHD profited more from distraction-inhibiting than from task-facilitating plans. Only in the distractioninhibiting implementation intention condition were the errors made during the naming task comparable to the amount of errors children made during the counting task. Thus, ignoring the distraction (i.e., type of numbers) is a more effective strategy than concentrating on the main task (i.e., counting the numbers).

\section{Implementation Intentions Facilitate Delay of Gratification Performance in Children with ADHD}

Go/NoGo and delay of gratification paradigms have one fundamental characteristic in common: In both tasks, performance requires controlling a prepotent response, whether it is producing a behavioral response in the $\mathrm{Go} /$ NoGo task (i.e., pressing the key although the NoGo signal indicates that the response has to be inhibited) or attending to the immediate reward in the delay of gratification task (i.e,, grabbing the immediate reward although the delayed reward is more valuable). Not surprisingly then, performance on both tasks have been linked to activity in similar areas in the prefrontal cortex (Eigsti et a1. 2006; Mischel \& Ayduk, 2002). In the same vein, stop and delay of gratification paradigms have both been used to measure impulsivity, even though these two types of tasks may be suited particularly well for assessing one rather than the other aspect of impulsivity as described in the literature. These aspects include (a) the ability to collect and evaluate information before reaching decisions; (b) the ability to choose larger delayed rewards over small immediate rewards; and (c) the ability to suppress motor responses that have been rendered prepotent (Chamberlain \& Sahakian, 2007). In sum, Go/NoGo task and 
delay of gratification paradigms seem to measure aspects of cognitive functioning that pertain to impulsivity.

The aim of the following two studies was to explore whether if-then plans help children with ADHD in a delay of gratification paradigm (Gawrilow, Gollwitzer, \& Oettingen, 2009). Specifically, children with and without ADHD were confronted with a computerized delay of gratification game, modeled after paradigms used in experiments by Mischel and colleagues (Mischel, Shoda, \& Rodriguez, 1989) and by Sonuga-Barke and colleagues (Sonuga-Barke, Taylor, Sembi, \& Smith, 1992). For this task, children had to decide between an immediate and less valuable (red pictures showing vehicles or animals with a value of one point) or a delayed and more valuable gratification (blue pictures showing vehicles or animals with a value of three points) presented on a computer screen. As an incentive, children could exchange their points for money at the end of the experiment.

Participants in the first study were children with ADHD in a German medical center specializing in the treatment of children with ADHD. Children were randomly assigned to three conditions: One-third of the children received a neutral sentence ("Red pictures are one point, blue pictures are three points") and one-third received a sentence with a goal intention ("I will earn as many points as possible"). The remaining children received the goal intention and an additional implementation intention ("If a red picture appears, then I. will wait for the blue one."). As compared to the neutral sentence (control) group, the children benefited (i.e., made more points) from the implementation intention but not from the mere goal intention.

In a second study we invited not only children with $\mathrm{ADHD}$, but we compared children with ADHD to children without any known psychological disturbances. Again, children were randomly assigned to the same three conditions (neutral vs. goal intention instruction vs. goal intention plus implementation intention instruction) as in the previous study. Both children with and without ADHD benefited from having formed implementation intentions.
Specifically, children who had formed an ifthen plan, in contrast to those with a neutral statement or mere goal intention, managed to delay gratifications better during the game and therefore ultimately earned more money at the end of the game. Consistent with the previous study, goal intentions were not superior to neutral instructions in children with ADHD; thus formulating the goal to obtain more points and therefore a bigger reward was not helpful for delaying gratifications in children with ADHD. Furthermore, implementation intentions enabled children with ADHD to wait significantly more often in the second half compared to the first half of the game. 'Thus, children with ADHD can use making if-then plans as a strategy to sustain their waiting behavior for delayed rewards over a longer period of time although impulsivity is one of the main symptoms of ADHD.

\section{Implementation Intentions Facilitate Set-Shifting and Multitasking in Children with ADHD}

Children with ADHD not only show deficits in inhibitory control as measured by Go/NoGo and delay of gratification paradigms, but also struggle on other neuropsychological tasks (Halperin \& Schulz, 2006). We therefore inves. tigated the effect of implementation intentions on executive functioning in two more studies: in tasks assessing set-shifting and in tasks that require multitasking.

In the set-shifting study, we presented chil dren with ADHD with a slightly modified version of a WCST (Gawrilow, Oettingen, 8 Gollwitzer, 2009a, Study 2). At the outset, the children received several stimulus cards and a stack of additional cards. The children were then asked to match each of the additional cards to one of the stimulus cards, but received no instruction (i.e., rule) on how to matel the cards; they did however receive immed ate feedback from the experimenter about the correctness of their choice. Following a dild's 10 th correct match, the experimenter changed the rule. Prior to the task, one-third of the children were randomly assigned to a nettis instruction condition ("The additional ofots 
Ud to be matched to the cards on the table."), tettird to a goal intention condition "I will Whas many cards as possible with the cor(actrule."), and the remaining children to an tiiplementation intention condition ("And if ny tule is wrong, then I will try another rule inediately."). The implementation intention roup ended up with a significantly lower level of 1 reservation errors in relation to the percent ge of total errors than both the goal intention ind control instruction group. This significant nin effect implies that children with ADHD at benefit from implementation intentions in bifting cognitive sets as measured with a modIffed WCST.

In the multitasking study (Gawrilow, Oettingen, \& Gollwitzer, 2009b), we used a multitasking paradigm modeled after the Six dlements Test (SET). Children received three different tasks that were associated with different colors (i.e., green, blue, \& red) and every task consisted of two parts. Children were instructed to work on two green tasks (consisting of counting and calculating items), on two blue tasks (consisting of naming items), and two red tasks (consisting of sorting items). In our modified version, children worked on each of the six tasks at least twice over a period of 10 minutes without working on a task with the same color consecutively. Children with and without ADHD were randomly assigned to a neutral instruction (There are a lot of tasks and it is not allowed to work on two tasks with the same color consecutively."), goal intention instruction ("I will try to solve at least 10 items of every color alternating."), or an additional implementation intention ("And as soon as I have solved 10 items of a color, then I will switch to another color."). Children with ADHD achieved a higher score as compared to the control group only with implementation intentions; for children without $\mathrm{ADHD}$, this was true already with goal intentions.

\section{CONCLUSION AND OUTLOOK}

We have argued that making if-then plans is an effective strategy to make goal-striving effective so that getting started, staying on track, calling a halt, and not overextending oneself when striving for one's goals become more manageable. We have then reported evidence that if-then planning holds up its promise even when goal-striving is challenged by the lack of relevant skills, competitive opponents, habitual antagonistic responses, or a psychological disorder handicapping action control in general (i.e., ADHD). Given this track record, if then planning qualifies as an effective goal-striving strategy to be taught to people in interventions to facilitate their everyday goal-striving. Such interventions need to create conditions where people are particularly motivated and capable to make if-then plans and where the effects of if-then plans are known to be particularly strong. This has recently been attempted in intervention studies that combined mental contrasting ( $\mathrm{MC}$; i.e., considering obstacles to a vividly imagined desired future goal state, Oettingen, Pak, \& Schnetter, 2001) and implementation intentions into one intervention (MCI-intervention) to promote exercising in middle-aged women (Stadler, Oettingen, \& Gollwitzer, 2009) and coping with the stressors of everyday life in college students (Oettingen et al., 2009).

\section{REFERENCES}

Aarts, H., Dijksterhuis, A. P., \& Midden, C. To plan or not to plan? Goal achievement of interrupting the performance of mundane behaviors. Eur J Soc Psychol 1999; 29: 971-979.

Achtziger, A., Gollwitzer, P. M., \& Sheeran, P. Implementation intentions and shielding goal striving from unwanted thoughts and feelings. Pers Soc Psychol Bull, 2008; 34: 381-393.

Armitage, C. Y. Evidence that implementation intentions reduce dietary fat intake: $A$ randomized trial. Health Psychol 2004; 23: 319-323.

American Psychiatric Association. Diagnostic and statistical manual of mental disorders, 4 th ed. Washington, DC: Author, 1994.

Bargh, J. A., \& Chartrand, 'T. I, The mind in the middle. A practical guide to priming and automaticity research. In: Reis, H. T. \& Judd, C. M. (Eds.), Handbook of research methods in social and personality psychology. Cambridge, UK: Cambridge University Press, 2000: pp. 253-285. 
Barkley, R. A. Behavioral inhibition, sustained attention, and executive functions: Constructing a unifying theory of ADHD. Psychol Bull 1997; 121: $65-94$.

Bayer, U. C., Achtziger, A., Gollwitzer, P. M., \& Moskowitz, G. Responding to subliminal cues: Do if then plans cause action preparation and initiation without conscious intent? Soc Cogn 2009; 27: 183-201.

Bayer, U. C., Gollwitzer, P. M., \& Achtziger, A. Staying on track: Planned goal striving is protected from disruptive internal states. J Exp Soc Psychol, in press.

Bayer, U. C., \& Gollwitzer, P. M. Boosting scholastic test scores by willpower: The role of implementation intentions. Self Identity 2007; 6: 1-19.

Berg, E. A. A simple objective test for measuring flexibility in thinking. J Gen Psychol 1948; 39: $15-22$.

Bottom, W. P., \& Studt, A. Framing effects and the distributive aspect of integrative bargaining. Organ Behav Hum Decis Process 1993; 56: $459-474$.

Brandstätter, V., Lengfelder, A., \& Gollwitzer, P. M. Implementation intentions and efficient action initiation. J Pers Soc Psychol 2001; 81; 946 960.

Brockner, J. The escalation of commitment to a failing course of action: Toward theoretical progress. Acad Manage Rev 1992; 17: 39-61.

Burgess, P. W. Strategy application disorder: The role of the frontal lobes in human multitasking. Psychol Res 2000; 63: 279-288, .

Burgess, P. W., Simons, J. S., Dumontheil, I., \& Gilbert, $S$. J. The gateway hypothesis of rostral PFC function. In: Duncan, I., Phillips, L., \& McLeod, P. (Eds.), Measuring the mind: Speed control and age. Oxford, UK: Oxford University Press, 2005: pp. 215-246.

Carretié, L., Hinojosa, J. A., Martín-Loeches, M., Mercado, F., \& Tapia, M.Automatic attention to emotional stimuli: Neural correlates. Hum Brain Mapp 2004; 22: 290-299.

Chamberlain, S. R., \& Sahakian, B. J. The neurop. sychiatry of impulsivity. Curr Opin Psychiatr 2007; 20: 255-261.

Clarke, C., Prior, M., \& Kinsella, G. Do executive function deficits differentiate between adolescents with ADHD and Oppositional Defiant/ Conduct Disorder? A neuropsychological study using the Six elements test and Hayling sentence completion test. J Abnorm Child Psychol 2000; 28: 403-414.
Cohen, A.-L., Bayer, U. C., Jaudas, A., \& Gollwitzer, P. M. Self-regulatory strategy and executive control: Implementation intentions modulate task switching and Simon task performance. Psychol Res 2008; 72: 12 26.

Cohen, J. A power primer. Psychol Bull 1992; 112 : 155-159.

Covassin, 'T., \& Pero, $S$. The relationship between self-confidence, mood state, and anxiety among collegiate tennis players. I Sport Behav 2004; 27: 230-242.

Eigsti, I., Zayas, V., Mischel, W., et al, Predictive cognitive control from preschool to late adoles. cence and young adulthood. Psychol Sci 2006; 17: $478-484$.

Epstein, J. N., Erkanli, A., \& Conners, C. K. Relations between continuous performance test performance measures and ADHD behaviors. J Abnorm Child Psychol 2003; 31: 543-554.

Frazier, T. W., Youngstrom, E. A., Glutting, J. J., \& Watkins, M. W. ADHD and achievement: Meta-analysis of the child, adolescent, and adult literatures and a concomitant study with college students. J Learn Disab 2007; 40: 49-65.

Gawrilow, C., \& Gollwitzer, P. M. Implementation intentions facilitate response inhibition in children with ADHD. Cognit Ther Res 2008; 32: 261-280.

Gawrilow, C., Gollwitzer, P. M., \& Oettingen, $G$. If -then plans benefit delay of gratification per formance in children with and without ADHD. Cognitive Therapy and Research, in press.

Gawrilow, C., Oettingen, G, \& Gollwitzer, $P$ If-then plans benefit executive functions in children with ADHD. Manuscript submitted for publication, $2009 \mathrm{a}$.

Gawrilow, C., Oettingen, G., \& Gollwitzer, P M Implementation intentions support multitast ing in children with ADHD. Manuscript it preparation, $2009 \mathrm{~b}$.

Gilbert, S. J., Gollwitzer, P. M., Cohen, Al. Oettingen, G., \& Burgess, P. W. Separablebran systems supporting cued versus self-initited realization of delayed intentions. J Exp Psychol Learn Mern Cogn 2009; 35: 905-915.

Gollwitzer, P. M. Goal achievement: The of of intentions. Eur Rev Soc Psychol 1993 4 $141-185$.

Gollwitzer, P. M. Implementation intentionts. Strong effects of simple plans. Am Psycto 1999; 54: 493-503.

Gollwitzer, P. M., \& Bayer, U. C. Becoming obotto person without changing the self. Paper present 
the Self and Identity Pre-conference of the Annual Meeting of the Society of Experimental 80ial Psychology, Atlanta, Georgia, October

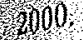

Golititzer, P. M., \& Brandstätter, V. Implementa ton Intentions and effective goal pursuit. J Pers Soc Psychol 1997; 73: 186-199.

7) IWilzer, P. M., \& Schaal, B. Metacognition in action: The importance of implementaton intentions. Pers Soc Psychol Rev 1998; 2; $224-136$.

Gollwitzer, P. M., \& Sheeran, P. Implementation ntentions and goal achievement: A meta analysis of effects and processes. Adv Exp Soc psychol 2006; 38: 69-119.

Halperin, J. M., \& Schulz, K. P. Revisiting the role of the prefrontal cortex in the pathophysiology of ADHD. Psychol Bull 2006; 132: 560-581.

Ianegby, R., \& Tenenbaum, G. Blame it on the racket: Norm-breaking behaviors among funior tennis players. Psychol Sport Exerc 2001; 2.117-134.

Heinderson, M. D., Gollwitzer, P. M., \& Oettingen, G. Implementation intentions and disengagement from a failing course of action. I Behav Decis Mak 2007; 20: 81-102.

Uinton, D., Nathan, M., \& Bird, B. Panic probes and the identification of panic: A historical and cross-cultural perspective. Cul Med Psychiatry 2002; 26: 137-153.

Holland, R. W., Aarts, H., \& Langendam, D. Breaking and creating habits on the working floor: A field experiment on the power of implementation intentions. J Exp Soc Psychol 2006; 42: 776-783.

Homack, S., \& Riccio, C. A. A meta-analysis of the sensitivity and specificity of the Stroop Color and Word Test with children. Arch Clin Neuropsychol 2004; 19: 725-743.

Hoza, B., Mrug, S., Gerdes, A. C., et al. What aspects of peer relationships are impaired in children with attention-deficit/hyperactivity disorder? ) Consult Clin Psychol 2005; 73: 411-423.

Lengfelder, A., \& Gollwitzer, P. M. Reflective and reflexive action control in patients with frontal brain lesions. Neuropsychology 2001; 15: $80-100$.

Logan, G. D., \& Cowan, W. B. On the ability to inhibit thought and action: $A$ theory of an act of control. Psychol Rev 1984; 91: 295-327.

Milne, S., Orbell, S., \& Sheeran, P. Combining motivational and volitional interventions to promote exercise participation: Protection motivation theory and implementation intentions. Br J Health Psychol 2002; 7: 163-184.

Mischel, W., \& Ayduk, O. Self-regulation in a cognitive-affective personality system: Attentional control in the service of the self. Self Identity 2002; 1: 113-120.

Mischel, W., Shoda, Y., \& Rodriguez, M. L. Delay of gratification in children. Science $1989 ; 244$ : 933-938.

Muraven, M., \& Baumeister, R. F. Self-regulation and depletion of limited resources: Does selfcontrol resemble a muscle? Psychol Bull 2000; 126: 247-259.

Murgraff, V., White, D., \& Phillips, K. Moderating binge drinking: It is possible to change behav. ior if you plan it in advance. Alcohol Alcohol $1996 ; 6: 577-582$.

Oettingen, G., Barry, H., Guttenberg, K., \& Gollwitzer, P. M. Self-regulation of time management: Mental contrasting with implementation intentions. Manuscript submitted for publication, 2009.

Oettingen, G., Hönig, G., \& Gollwitzer, P. M. Effective self-regulation of goal attainment. Int J Educ Res 2000; 33: 705-732.

Oettingen, G., Pak, H., \& Schnetter, K. Selfregulation of goal-setting; Turning free fantasies about the future into binding goals. $J$ Pers Soc Psychol 2001; 80: 736-753.

Olekalns, M. Situational cues as moderators of the frame-outcome relationship. Br J Soc Psychol 1997; 36: 191-209.

Orbell, S., \& Sheeran, P. Motivational and volitional processes in action initiation: A field study of the role of implementation intentions. J App Soc Psychol 2000; 30:780-797.

Orbell, S., Hodgkins, S., \& Sheeran, P. Implementation intentions and the theory of planned behavior. Pers Soc Psychol Bull 1997; 23: 945-954.

Oosterlaan, J., Logan, G. D., \& Sergeant, J. A. Response inhibition in $A D H D, C D$, comorbid $A D H D+C D$, anxious and normal children: a meta-analysis of studies with the stop task. J Child Psychol Psychiatr 1998; 39: $411-425$

Parks-Stamm, E. J., Gollwitzer, P. M., \& Oettingen, G. Action controlby implementation intentions: Effective cue detection and efficient response initiation. Soc Cogn 2007; 25: 248-266.

Patterson, C. J., \& Mischel, W. Effects of temptationinhibiting and task-facilitating plans of selfcontrol. J Pers Soc Psychol 1976; 33: 209-21\%. 
Raven, J. C. The Raven's progressive matrices: Change and stability over culture and time. Cogn Psychol, 2000; 41: 1-48.

Rosvold, H. E., Mirsky, A. F., Sarason, I., Bransome, E. D., \& Beck, L. H. A continuous performance test of brain damage. J Consult Psychol 1956; 20: $343-350$.

Rubia, K., Russell, T., Overmeyer, S., et al. Mapping motor inhibition: conjunctive brain activations across different versions of $\mathrm{Go} / \mathrm{NoGo}$ and stop tasks. Neurolmage 2001; 13: 250 261.

Schweiger Gallo, I., Keil, A., McCulloch, K. C., Rockstroh, B., \& Gollwitzer, P. M. Strategic automatization of emotion control. J Pers Soc Psychol 2009; $96: 11$-31.

Sheeran, P., \& Orbell, S. Using implementation intentions to increase attendance for cervical cancer screening. Health Psychol 2000; 19: 283-289.

Sheeran, P., Webb, T', L., \& Gollwitzer, P. M. The interplay between goal intentions and implementation intentions. Pers Soc Psychol Bull 2005; 31: 87-98.

Simon, J. R. The effects of an irrelevant directional cue on human information processing. In: Proctor, R. W. \& Reeve, T. G. (Eds.), Stimulusresponse compatibility: An integrative perspective. Amsterdam: North-Holland, 1990: pp. 31-86.

Sonuga-Barke, E. J. S., Taylor, E., Sembi, S., \& Smith, I. Hyperactivity and delay aversion-1. The effect of delay on choice. I Child Psychol Psychiatry 1992; 33: 387-398.
Stadler, G., Oettingen, G., \& Gollwitzer, P. M. Effects of a self-regulation intervention on women's physical activity. J Prevent Med 2009; 36: 29-34.

Stroop, J. R. Studies of interference in serial verbal reactions. J Exp Psychol 1935; 28; 643-662.

Trötschel, R., \& Gollwitzer, P. M. Implementation intentions and the willful pursuit of goals in negotiations. J Exp Soc Psychol 2007; 43; 519-598.

Webb, T. L., \& Sheeran, P. Can implementation intentions help to overcome ego-depletion? J Exp Soc Psychol 2003; 39: 279-286.

Webb, T. L., \& Sheeran, P. Identifying good opportunities to act: Implementation intentions and cue discrimination. Eur \} Soc Psychol 2004; 34: 407-419.

Webb, T. L., \& Sheeran, P. Does changing behavioral intentions engender behavior change? $\mathrm{A}$ meta-analysis of the experimental evidence. Psychol Bull 2006; 132: 249-268.

Webb, T. L., \& Sheeran, P. How do implementation intentions promote goal attainment? A test of component processes. J Exp Soc Psychol 200\%, 43: 295-302.

Webb, T. L., \& Sheeran, P. Mechanisms of imple. mentation intention effects: The role of goal intentions, self-efficacy, and accessibility of plan components. Br J Soc Psychol 2008; 47: 373-395.

Wughalter, E. H., \& Gondola, J. C. Mood states of professional female tennis players. Percept Motor Skills 1991; 73: 187-190. 